\title{
Article
}

\section{The Impact of Overseas Warehouse on Cross-border E-Commerce Exports from the Perspective of System Dynamics}

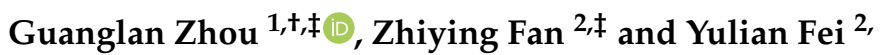 \\ 1 School of Center for Modern Trade and Commerce Research, Zhejiang Gongshang University; \\ guanglanzhou@mail.zjgsu.edu.cn ${ }^{2}$ Department of Management Engineering and E-Commerce \\ Zhejiang Gongshang University; \\ * Correspondence: 1299212386@qq.com
}

\begin{abstract}
The novel coronavirus pneumonia epidemic is still raging around the world. Therefore, during the period of global pandemic, maintaining the normal circulation of medicine and health fields is the key to fight against the epidemic. This paper-based on relevant data such as the export volume of cross-border e-commerce in Hangzhou, China from 2015 to 2019, the article uses system dynamics modeling to explore the impact of overseas warehouse services on cross-border e-commerce export transactions. Studies have shown that the introduction of overseas warehouses has significantly improved customer satisfaction and improved the quality of cross-border logistics services, which has a positive impact on cross-border e-commerce export transactions. Through sensitivity analysis, it can be seen that under the same conditions, the efficiency of customs clearance has the greatest impact on overseas warehouse services. Therefore, when allocating various investments in overseas warehouses, you can favor the customs clearance process to enhance the competitiveness of the cross-border e-commerce market and provide a feasible experience for healthcare supplies export from cross-border e-commerce.
\end{abstract}

Keywords: System Dynamics; Overseas Warehouse; Cross-border E-commerce; Logistics Service Quality; Healthcare Supplies Export.

\section{Introduction}

With the development of social progress and economic globalization, cross-border e-commerce, as a new type of market segment business behavior, has grown rapidly. In 2019, China's cross-border e-commerce transactions jamounted to 10.8 trillion yuan. Among them, cross-border e-commerce exports amounted to 8.03 trillion yuan, a year-onyear increase of approximately 13.09 percents. The industrial characteristics of China's Zhejiang Province, which is dominated by light industry, are highly compatible with the development concept of cross-border e-commerce, and therefore developed the crossborder e-commerce industry in 2015. Hangzhou, Zhejiang Province, as the first batch of cross-border e-commerce comprehensive pilot zones established in China, has gradually formed a comprehensive development model integrating system innovation, management innovation, collaborative innovation, and service innovation through continuous exploration and development. With the unique advantages of fewer intermediate links, more convenient transaction forms and cheaper transaction prices, and the ability to further extend the industry to the cross-border warehousing industry and derive various value-added services, the overseas warehouse service not only reduces the possibility of international freight forwarders being divided into markets in the new environment but also takes the opportunity to integrate other markets and accelerate development, becoming an important way of China's import and export trade day by day. The new environment not only reduces the possibility of the international freight forwarding industry is divided into markets but also can take advantage of the opportunity to integrate other markets, It has gradually become an important way of import and export 
trade. With the spread of the epidemic, the import and export demand of pharmaceutical products has further increased, and the establishment of overseas warehouses can also provide an important guarantee for the circulation of pharmaceutical products.

biblatex ref

\section{Iiterature Review}

The rapid development of cross-border e-commerce has also presented new opportunities and challenges to the cross-border logistics system. Cross-border e-commerce faces the global economic market, the transaction mode is complex and changeable, and the risk coefficient of logistics is also higher.[1,2] Gomez-Herrera et al. (2014) And by using of e-commerce can effectively reduce transaction costs and increase the diversity of supply, but it is also limited by some trade barriers.[3] Establishing overseas warehouses in the destination countries can help cross-border B2C exporters gather information on logistics and distribution, logistics and transportation, customs policies and other related commodities in the destination countries, improve their localized logistics service capabilities, and have a significant impact on the performance of cross-border B2C exporters.[4]Therefore,Some scholars propose that the purpose of sharing storage space, reducing labor costs and warehouse construction costs can be achieved by creating a comprehensive service platform for overseas warehouses and establishing shared overseas warehouses.[5] China's traditional trade in goods cannot meet the needs of all parties in cross-border e-commerce transactions. The use of centralized transportation in overseas warehouses can effectively reduce transportation costs, and localized distribution can also shorten the waiting time of consumers, reduce the rate of damage and loss, and improve consumer satisfaction.[6]

Overseas warehouses are essentially a technology-intensive and capital-intensive enterprise, relying on large amounts of capital and human resources. The use of different economic entities in different countries makes it challenging to implement a centralized warehousing strategy overseas.[7] And then, Some scholars suggest that using the theory of parallel coupling and symbiosis to design a cross-border logistics collaborative management model.[8] The government and third-party cross-border e-commerce platforms jointly build public warehouses and establish overseas warehouse alliances, which are also important ways to offset the cost of the initial warehouse building.[9] Benefitsharing and risk-sharing mechanisms can also be promoted through the PPP model to reduce market risks and thus alleviate cost pressures.[10] Secondly, some scholars, when designing and formulating the index system for the development of cross-border e-commerce comprehensive pilot zone, found that the different calibers of statistical scope and statistical classification among customs, inspection and quarantine, taxation, and industry and commerce departments made it difficult to obtain relevant data resources. [11] Moreover, the statistical scope and boundary of cross-border e-commerce have not been fully standardized, especially the customs clearance methods and logistics channels have a lot of difficulties. [12] The development of e-commerce depends heavily on the compatibility of hardware settings, and therefore requires active government participation and encouragement of e-commerce development.[13]

With the rapid development of cross-border logistics, market competition continues to intensify, and the corresponding logistics service quality needs to be improved. Perreault and Russ once proposed the 7R theory, that is, the process of logistics service quality is like the quantitative process of value creation of logistics enterprises, and logistics enterprises need to provide a quantitative consideration index.[14] With the rapid development of the logistics industry, the quality of logistics services should also attract attention.[15] The study of express logistics companies found that the quality of logistics services also has a significant impact on logistics profits.[16]

Today, the quality of logistics services has become the key to the development of cross-border e-commerce enterprises. The overseas warehouse service as a new type of special cross-border logistics way, for its service quality research is less, for the overseas 
warehouse service quality for cross-border e-commerce trading scale research is few. This paper takes the service quality of overseas warehouse in Hangzhou, China as the object of study, and through sensitivity analysis, adjusts the proportion of business investment in various aspects of the overseas warehouse, to analyze the impact of different proportions of investment on customer satisfaction, to improve the quality of overseas warehouse logistics services, and thus make cross-border e-commerce transaction volume to be improved.

\section{System Dynamics Modeling}

System dynamics is a cross-discipline that analyzes information feedback. It is especially suitable for non-linear systems. It can directly show the relationship between various influencing variables. Therefore, this article is based on the five-year statistical data of Hangzhou, China from 2015 to 2019, including Hangzhou Statistical Yearbook, Hangzhou Post Administration, China Statistical Information Network, National Bureau of Statistics, and existing literature research results, through the system dynamics model And Vensim simulation analysis, starting from the factors that affect the quality of overseas warehouse services, taking Hangzhou as an example, to explore the impact of overseas warehouses on cross-border e-commerce export transactions.

\section{System dynamics modeling ideas}

The booming growth of cross-border e-commerce has also placed higher demands on logistics and distribution. The public focus has also shifted from the cross-border e-commerce platform industry to the provision of services. For cross-border e-commerce, logistics is a bridge connecting sellers to sellers, and the quality of logistics services is key to customer satisfaction, repeat purchases and other issues. Therefore, logistics service is an important intermediate link in cross-border e-commerce. This paper will analyze the consideration factors of logistics service quality in the context of cross-border e-commerce and analyze the impact of overseas warehouse service construction on cross-border e-commerce transaction volume through system dynamics modeling.

The overseas warehouse model began with Amazon, which has established 49 warehouse operation centers around the world in succession at the end of 2013, and China has also started to pay attention to and build overseas warehouses since 2014 . According to easy warehouse research data statistics, in 2018, a total of 33 countries 158 overseas warehouse enterprises, building 353 overseas warehouses. In terms of the total area of overseas warehouses, the United States is still the absolute leader. But in recent years, Russia has also struggled to catch up, with the highest single warehouse area in the world. In contrast, China still has a lot of room for progress, "2019 China cross-border e-commerce development report" shows that in 2019, China's cross-border e-commerce transactions reached 10.8 trillion yuan, an increase of 16.7 percent year-on-year, crossborder e-commerce transactions accounted for the proportion of the scale of e-commerce transactions has been as high as 30.2 percent. Among them, cross-border e-commerce exports amounted to 8.03 trillion yuan, an increase of about 13.09 percent year-on-year.

In legal terms, an overseas warehouse is not just a warehouse for the storage of goods, but an entity that exists overseas.[17]In terms of current development, overseas warehouses are indeed constantly upgrading and expanding their business, no longer "warehouse" can contain the meaning. And overseas warehouse model of cross-border logistics operation process is increasingly cumbersome, the service level of each step will affect the final consumer consumption, should cause enterprises to pay attention to. According to Ai Media Consulting's "2019 Amony Consumers on Online Cross-Border E-commerce Improvement Demand Survey", 55.7percent of consumers believe that they need to protect genuine products, 37.4 percent chose better after-sales service, 32.8 percent chose more affordable prices, and 22.9 percent chose faster logistics. Based on the above analysis, this article will start with three factors: order processing, logistics and 
distribution, and service level, and analyze the impact of these three inputs on service quality in overseas warehouses.

The first is order processing, including order processing in a timely manner, accuracy, order satisfaction rate and other factors, order processing in a timely and accurate manner will affect the customer's first impression of the enterprise, and is therefore very important. Next is the logistics and distribution, including the products from domestic warehouses to overseas warehouses, overseas warehouse goods to the hands of consumers, consumer returns and other processes. Consumers want to be able to receive their products as soon as possible, but also to ensure that the product is intact. This requires overseas warehouse logistics to be able to do the best in terms of customs clearance speed and distribution efficiency. At present, most of the cross-border sea taotao platform return policy is not very clear, return process time and money is very high, so also limit the consumer's certain consumption. The overseas warehouse has a perfect reverse logistics system, for this kind of problem has improved. The last is the level of service, that is, a lower rate of packet loss, the timely update of information, the level of return and exchange. Overseas warehouse logistics is essentially still part of the tertiary industry, so the quality of service level is also a necessary part. These factors also ultimately affect the number of cross-border consumption of the final transaction. In order to explore the specific impact of overseas warehouse services on cross-border transactions, this paper adopts a system dynamics modeling approach and will conduct an in-depth analysis of this issue.

Before modeling, the system boundary problem also needs to be clarified first. Because the system will receive the joint influence of internal and external factors, so in order to simplify the system, this paper makes the assumption that the external factors do not affect the system, so the external factors are not considered here. In this paper, we mainly study the influence of logistics on the trading scale of cross-border e-commerce, which is mainly divided into three subsystems: order processing capacity, logistics and distribution level, and service quality.

\section{Principles of System Dynamics Modelling}

When constructing a system dynamics model, the following principles are usually followed.

1.Purpose principle.

When using SD modeling to study a problem, it is necessary to focus on the research problem and use the SD model to represent the researched problem.

2.The principle of simplicity.

The cross-border e-commerce system is a complete system, which is composed of many independent subsystems, and each element is independent of each other, and the hierarchical structure is clear.

3.The principle of effectiveness.

The model should be able to adapt to the actual situation, and can reliably reflect the current situation and future trends of the research problem.

\section{Causal Analysis}

In system dynamics, a cause-effect diagram shows the feedback relationship between factors within the system and can clearly show the logical variation between the variables. Based on the previous division of several subsystems of the system, the next step is therefore an in-depth analysis of each subsystem of the system.

(a) Order processing subsystem

The front of the overseas warehouse order processing work seems simple, but can have a high product satisfaction rate is difficult. As customer demand continues to change, how to choose products generally accepted by the public has become somewhat difficult, and once not accepted will lead to a backlog of overseas warehouse products, unsold, bringing business pressure. Overseas warehouse of many types of goods, 
according to the rate of product sales and unsold rate to start on the analysis, through data analysis advantages of strict control of product selection, real-time mastery of inventory information. For when to replenish the warehouse, how to replenish the warehouse and other issues also need to do a good job of warehouse management, to maximize returns and reduce risk. Secondly, the product into the warehouse to do a good job of splitting large packages of goods, orderly SKU barcode management, to ensure the uniqueness of the goods, in the receipt of user orders to send out accurate and timely goods.

(b) ogistics and distribution subsystem

Trade and logistics is a symbiotic relationship, and the two are complementary and mutually restraining. And with the rise of cross-border e-commerce transactions, cross-border logistics is bound to be taken seriously. Overseas warehouse seems to set up an inventory warehouse overseas, is actually set up an overseas agent, responsible for goods goods overseas warehousing, distribution, reverse logistics and other aspects of cross-border logistics into local distribution, so the distribution speed has also been greatly enhanced. At the same time, cross-border e-commerce logistics in the customs issues are also relatively harsh existence, each country's customs policy is different, different procedures, is bound to affect the distribution efficiency of logistics, but also led to a lot of labor, time investment. Through the establishment of overseas warehouses in various countries, we can promptly understand the policy changes in various countries, so as to make an effective response quickly and minimize the time delay on the customs process, and can combine each single commodity together to achieve economies of scale and enlarge the adjustable space of product prices. Some commodities, such as non-durable goods, have a high price elasticity of demand, and a small reduction in price is all that is needed to achieve a significant increase in demand, thereby increasing the scale of the transaction. Typically, overseas warehouses can reduce international logistics costs by about 30 percent, especially for bulk goods, and the cost advantage is more obvious. Secondly, reverse logistics issues are also being addressed, as the return and exchange process in traditional logistics is more complicated and freight costs are high, thus causing some consumers to be deterred. Under the overseas warehouse model, returns and exchanges can be returned directly to the local warehouses in various countries, without having to go through customs drift. Especially in the European and American markets, due to the superiority of the local return system, it is more necessary to do a good job in reverse logistics management. Through the construction of overseas warehouses, we can provide maximum reserves of different products to meet consumer demand, enhance brand image and corporate visibility, and thus increase the market share and sales level of enterprises.

(c) Service level subsystem

Traditional cross-border logistics due to the geographic distance between buyers and sellers, requiring multiple transfers to deliver products to consumers, so it is very easy to lose packages, damage and other situations, which seriously affects the customer's shopping experience, but also leads to a significant increase in logistics costs. Through the construction of overseas warehouses, cross-border logistics can be transformed into local logistics, reducing the number of transshipment, reducing the packet loss rate and other related issues. Secondly, the healthy development of cross-border e-commerce, but also inseparable from a high level of service, whether it is sales or responsible for after-sales staff are more contact with consumers, in solving problems in a good service attitude can enhance the impression of consumers on the company, improve the satisfaction of the company. In addition, the high management level of management personnel, able to grasp the problems encountered by consumers, timely response to customer needs, to promote the further development and progress of the enterprise. 


\section{Variable settings and model construction}

The above cause-effect diagram shows the logical relationship between each variable, and by analyzing the cause-effect loop diagram of each subsystem, the following system dynamics model of cross-border e-commerce transaction volume is constructed, which not only can mark the nature of the variables in each subsystem, but also can qualitatively analyze the quantity relationship between each variable, and then make a forecast of the future cross-border transaction scale. Based on the cause-effect diagram analysis of the three subsystems above, the variables of each system are integrated and an overall system flow diagram is established, in which the following variables are set for cross-border e-commerce transaction scale: cross-border e-commerce transaction scale, order volume, average cost of logistics, average waiting time for consumers, returns and exchanges, business revenue, investment in warehouse construction, customs clearance capacity, timely update of information, customer satisfaction, order processing accuracy, and the number of orders. Timeliness of order processing, logistics pressure, quality of employee service, etc. It covers rate variables, state variables, constants, auxiliary variables, etc., with transaction size as the flow position variable.

The system flow diagram constructed in this paper is shown in Figure 1.

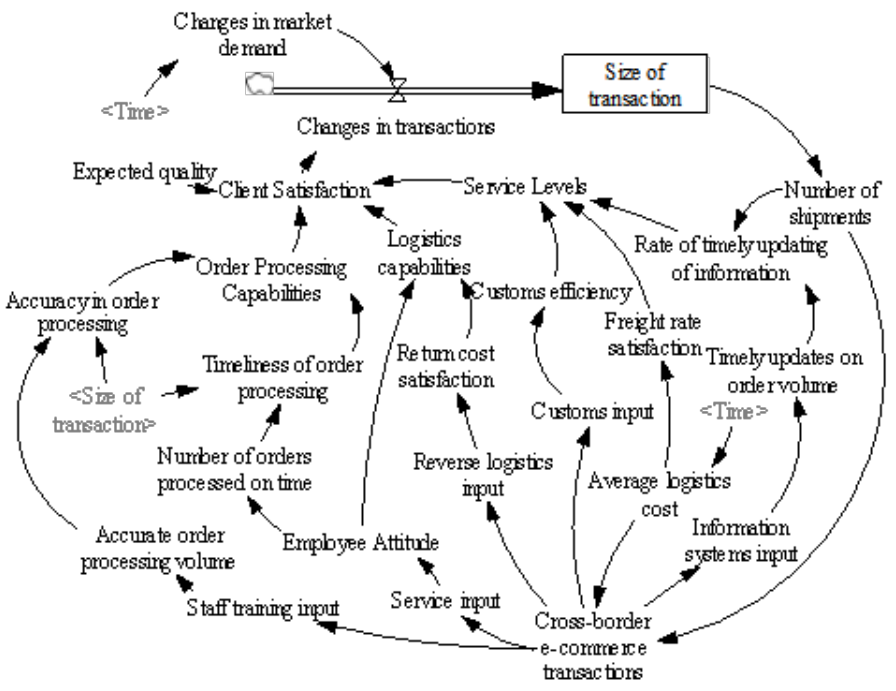

Figure 1. System flow diagram of overseas warehouse services.

The system flow diagram reflects the relationship between the variables, and to study the overall model order quantity changes, it is necessary to construct equations that describe the quantity relationship between the variables. In the process of system simulation, as the units and standards of each variable are different, it is necessary to standardize the process before model simulation to eliminate the influence of variable quantity on simulation results. The qualitative variables involved in the text mainly include: customs clearance capacity, customer satisfaction, etc., which are confirmed through questionnaires and other methods, so there is no need for scale-free processing. Whereas, when it is difficult to obtain accurate data due to the existence of some parameters, the data and simulation results are analyzed through the past years and continuously adjusted. The variable equations were inputted by vensim software.

Through the analysis of three subsystems: order processing, logistics and distribution, and service level, a system flow diagram of overseas warehouse services was constructed. Since the units of each variable and determination criteria are different, standardization should be done before establishing the equations. And then based on the system dynamics modeling principles, we established a model of the impact of overseas warehouse services on the scale of cross-border e-commerce transactions. And whether 
Table 1. Comparison of historical simulation results with realistic results.

\begin{tabular}{c|c|c|c|c|c}
\hline Year & $\mathbf{2 0 1 5}$ & $\mathbf{2 0 1 6}$ & $\mathbf{2 0 1 7}$ & $\mathbf{2 0 1 8}$ & $\mathbf{2 0 1 9}$ \\
\hline Real Value & 22.73 & 60.60 & 70.22 & 80.20 & 95.53 \\
\hline Predicted Value & 22.73 & 59.28 & 73.15 & 80.12 & 93.52 \\
\hline Inaccuracies & 0 & 0.0217 & 0.0417 & 0.0001 & 0.0021 \\
\hline
\end{tabular}

the model can be applied in current situation, we need to go through a series of testing steps in the next chapter before we can reach a final conclusion.

\section{System Dynamics Simulation Experiments}

System dynamics models are used to analyze problems from a holistic and global perspective to systematically solve problems. Therefore, the system dynamics model is built to study the changes in the development trend of the research object over a period of time, rather than showing the specific value at a certain point in time. This paper is based on the modeling of the impact of overseas warehouse construction on the trading scale of cross-border e-commerce, and data collection and analysis with the websites of Hangzhou Customs statistics, Hangzhou Statistical Yearbook, Hangzhou Post Office, etc., so as to understand the impact of overseas warehouse construction on the role of cross-border e-commerce, and to facilitate the making of appropriate and reasonable and effective development goals.

The modeling sets the initial time INITIAL TIME=2015, the termination time FINAL TIME=2024, TIME STEP=1, and the time unit is year. After the system dynamics model is established, in order to ensure that the model can complete the simulation run correctly and smoothly, the model needs to be tested, the following validity test and historical test of the model.

\section{Historicity test}

Simulation experiments first of all require that the model can reflect the actual situation, and the simulation results obtained through the experiments cannot be too different from the actual situation, so the model needs to be tested historically to prove that the model is valid. In this paper, the transaction amount is chosen as the test variable, through the comparison between the real value and the experimental results, to test the authenticity and credibility of the model constructed in the text, the results are shown in Table 1 below. As shown above, the error range between the real results and the simulation results of transaction size are within 5 percent, which is within the acceptable range. It shows that the model does not differ much from the real data, thus it can prove that the construction of the model in the paper is reasonable and feasible. On this basis, the investigation of the influence on the service situation of the overseas warehouse in Hangzhou is in line with the real situation and has certain practical significance, so it has the basis for completing the subsequent simulation experiments.

\section{Systematic Results Analysis}

The purpose of the system dynamics modeling is to predict the development trend of the research object in the future period of time, through the simulation results of crossborder e-commerce transaction volume, it can be seen that after the adoption of overseas warehouse logistics service model, the transaction volume has an explosive growth, and then rose steadily. In 2013, Hangzhou became the first batch of cross-border e-commerce trade pilot zone, and also by the relevant national ministries and commissions as the e-commerce demonstration zone. By providing customs, logistics, finance, talent and other "one-stop" services, successfully attracted a large number of enterprises to join, at the same time there are also national policy bonuses to support the significant rise in cross-border e-commerce transactions in 2016. And then coincided with Brexit, the form of the global economic and trade market has become increasingly complex, in addition, 
due to factors such as trade frictions between China and the United States in recent years has also made demand sluggish, resulting in China as a whole, although cross-border e-commerce transaction volume has maintained growth, but the growth rate inevitably slowed down. The specific model results are shown in Figure 2.

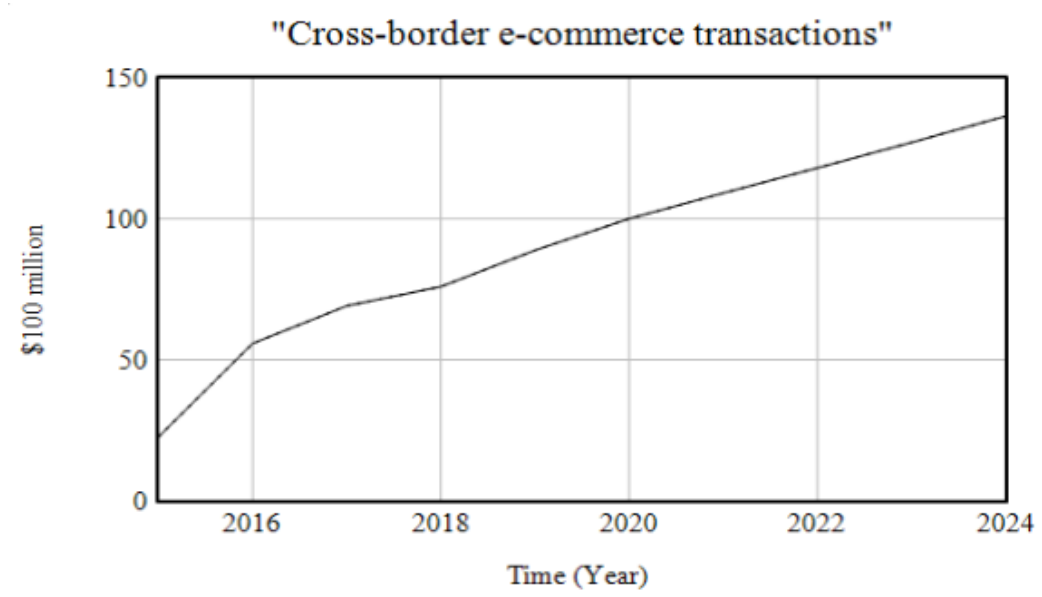

Figure 2. Trends in operating income.

Likewise, when the overseas warehouse logistics service was first adopted, both the management personnel and the consumers did not know much about it. In addition, because the overseas warehouse service involved many procedures and complicated processes, the quality of logistics service was not high and customer satisfaction was also poor at the beginning. But after the continuous development of each department and the friction and promotion, the quality of overseas warehouse service also climbed year by year, customer satisfaction has also been greatly improved, and with the gradual improvement of each business, on the right track, and infinitely more perfect, customer satisfaction gradually tends to stabilize. The specific model results are shown in Figure 3.

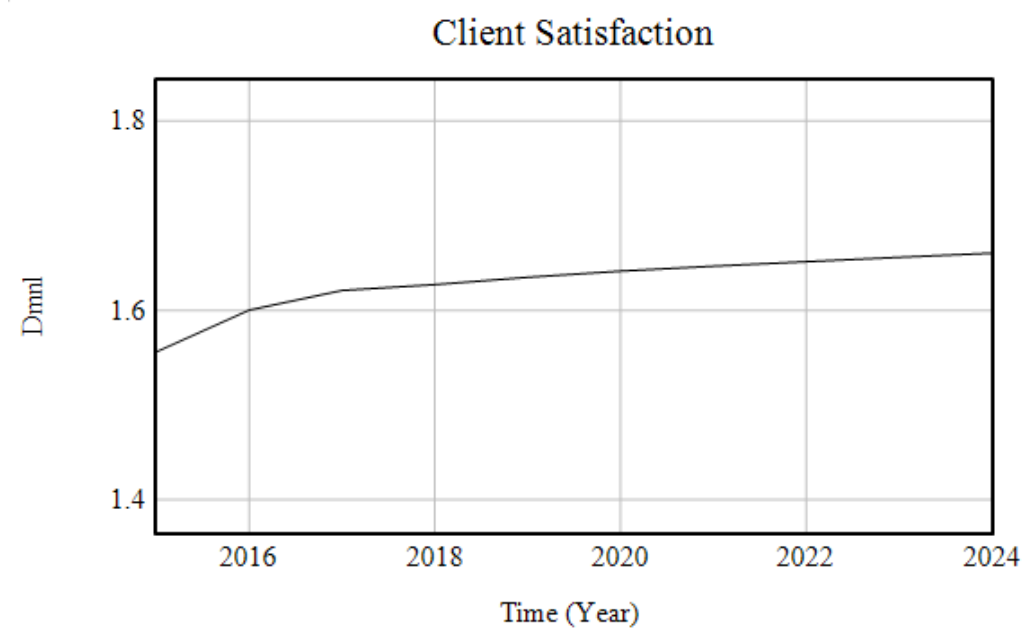

Figure 3. Evolution of customer satisfaction.

\section{Parameter Adjustment}

The system dynamics model can not only predict future trends, but also provide a more concrete basis for scientific decisions by observing the impact of variables on the system as a whole by changing parameter values. In vensim software, you can quickly simulate the changes of the transaction size in different situations by adjusting 
the relevant parameters, which helps the management to make a reasonable plan and corresponding adjustment for the company.

In the system dynamics model of this paper, five relevant business activities are mainly cited as input variables, namely: staff training, information system, reverse logistics, customs clearance and service. According to the data, the company invests 12 percent of its business income in these five areas of service construction in order to obtain better economic efficiency. How to allocate the investment in these five areas is the first issue that the company needs to consider. In order to facilitate the analysis and discussion, this paper allocates 12 percent of the business revenue equally to each project, and then observes the impact of each component on customer satisfaction by adding 0.01 percent of the revenue as new investment, as shown in Figure 4 below.

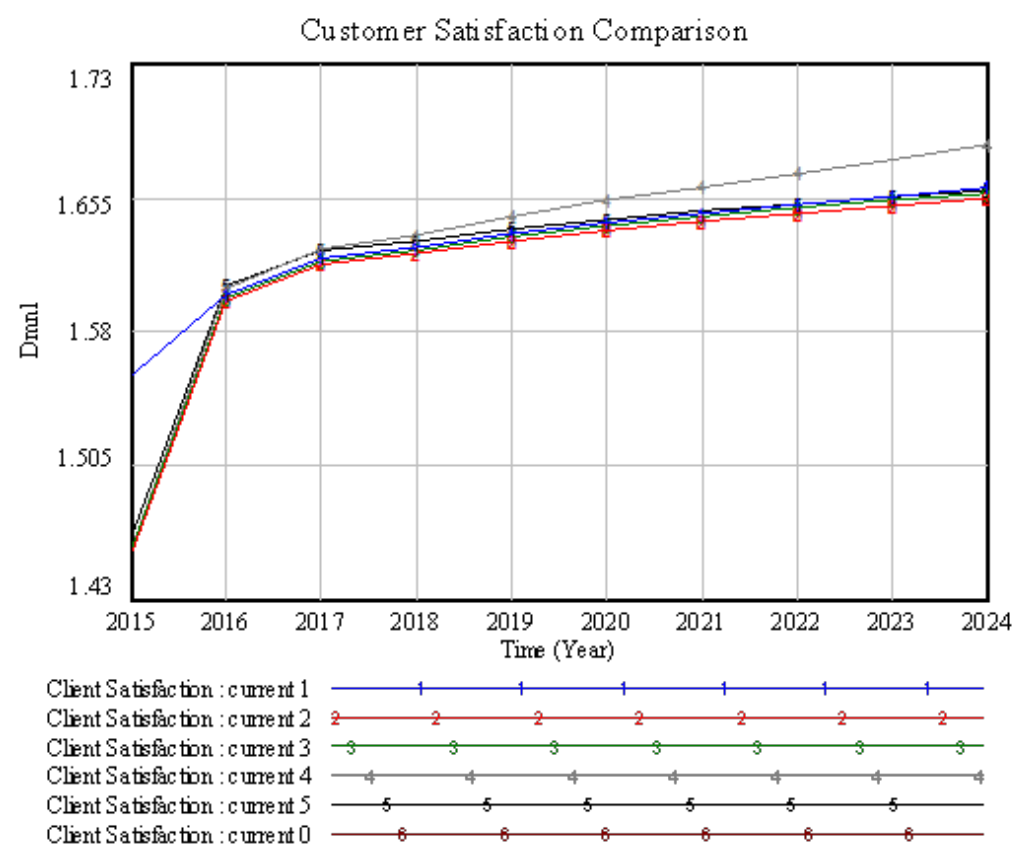

Figure 4. Changes in the impact of parameter adjustment on customer satisfaction.

Wherein, Current 5 represents the investment in staff training, information system, reverse logistics, customs clearance and service respectively, while Current0 represents the initial value (without 0.01 percent increase in investment). From the above figure, it can be seen that each process has a different impact on customer satisfaction when additional inputs are added to each process. Among them, the investment in customs clearance has the highest impact on customer satisfaction, while the additional investment in the other four aspects of business has little effect on customer satisfaction. Therefore, when making the corresponding decision plan, you can focus your investment on this area, while slowing down your investment in other areas. Targeting to maximize unit transaction volume. And when consumers have high satisfaction with the overseas warehouse services, then it will also eventually act on the transaction volume, occupy a higher market share and corporate city awareness, and establish a good image in the international market.

This is also illustrated by the graph (Figure 5) which shows that when the variable conditions are the same as described above, it is also the investment in customs clearance that has the most significant impact on cross-border e-commerce. In other words, there is a positive relationship between customer satisfaction and cross-border e-commerce turnover, and the increase in customer satisfaction also affects cross-border e-commerce turnover. 


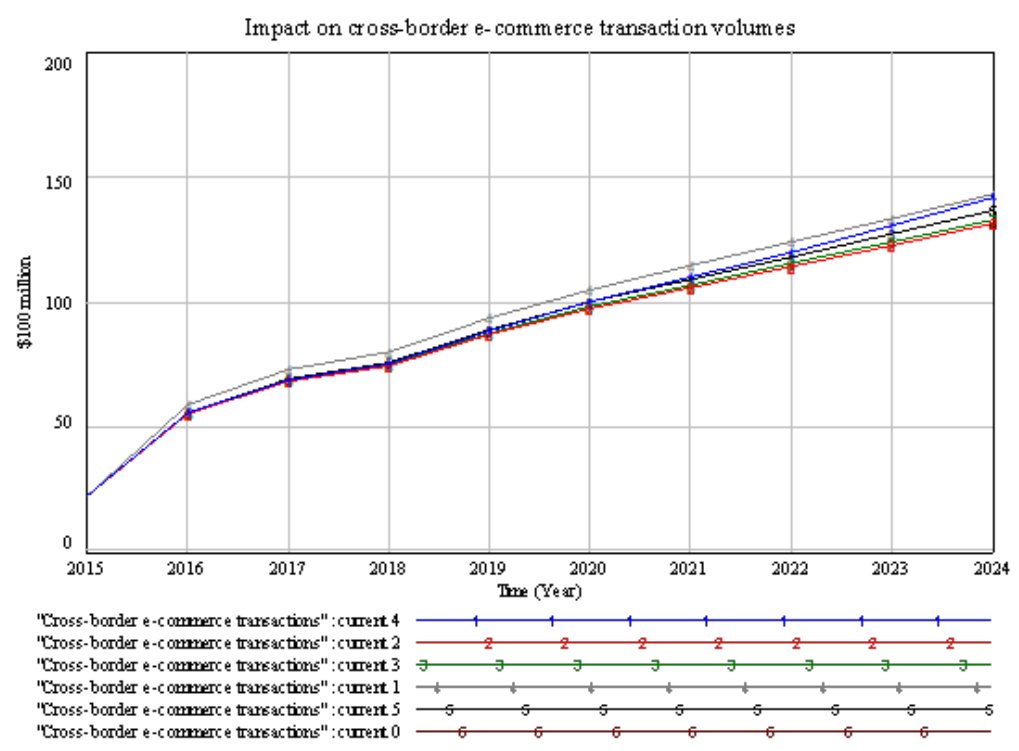

Figure 5. Impact on cross-border e-commerce transaction volume.

After passing the validity test and historical test, it can be found that the model built in this paper has a certain authenticity and reasonableness, so it is also meaningful to use this model for the subsequent related realistic analysis. Through the model simulation results can be made to infer that the economic expectations of cross-border e-commerce development is still good. After adjusting the parameters and increasing the proportion of investment in each business of overseas warehouse services, it can be seen that factors such as customs clearance efficiency have the greatest influence on consumer satisfaction and the change of cross-border e-commerce transaction volume. In the future, special attention should be paid to issues such as customs clearance efficiency and policies to maximize profits and social benefits.

\section{Recommendations}

Based on the above research and argumentation, this article also gives relevant suggestions:

(a) The customs clearance process of the cross-border e-commerce industry requires independent declaration and processing by cross-border e-commerce companies, which often causes companies to face various customs risks and affects the efficiency of corporate trade exports. Therefore, cross-border e-commerce companies must establish a customs early warning system to keep abreast of policy changes and reasonably avoid policy risks. At the same time, they can choose overseas agent service providers to assist in completing the customs clearance process. In addition, relevant departments should also actively implement a new type of customs supervision, implement centralized declarations, policy support, and tax incentives to improve the efficiency of customs clearance. Through the mutual cooperation of the government and enterprises, the advantages of overseas warehouses can be maximized.

(b) In a customer-led "pull" supply chain system, overseas warehouses can grasp customer needs in a timely manner, but the high investment in the initial stage of overseas warehouse construction has also caused many companies to stay away. In order to achieve synergy, it can be achieved through skill sharing, resource sharing, strategic alignment, integration of parties, and negotiation.[18] Therefore, in the case of limited development of the enterprise itself, it can make changes through multi-party cohesion and grouping. All enterprises share risks, share benefits, give full play to their strengths, realize division of labor and cooperation, and reduce the inherent costs of enterprises.

(c)The logistics industry belongs to the tertiary industry, and the improvement of service level has an obvious role in promoting the development of enterprises. While 
cross-border logistics is developing local services, the sinking of e-commerce logistics channels has also become a new development trend. Through the use of big data, cloud computing, artificial intelligence and other technologies, the advantages of overseas warehouses can be maximized to achieve The precise placement of products and the determination of the best replenishment cycle, while effectively reducing the company's operational risks and inventory costs, and optimizing the company's capital flow management.

\section{Conclusions}

(a)Based on the current economic development trend of Hangzhou, it can be found that the growth of its cross-border e-commerce export transaction volume has been stable, but the growth rate has slowed down, and the simulation results also illustrate this point. It can be seen that the system dynamics model cannot fully simulate reality. However, the simulation results are highly reliable and have a certain reference value. Then, by adjusting the equations of various parameter variables, the model can be made more accurate and in line with the actual situation.

(b) Through the simulation results of the model, a certain predictive analysis of the scale of cross-border e-commerce export transactions in Hangzhou is also carried out, and a separate analysis of some of the influencing variables will help us to look at the data performance more systematically and comprehensively. The simulation results show that by increasing the investment in customs clearance, customer satisfaction can be maximized, which in turn has a positive impact on the service quality of overseas warehouses, and makes cross-border e-commerce export transactions soar. This is also a new way that can not be ignored for the healthcare circulation industry.

Funding: This research was funded by China Statistical Bureau Project (2020LY102) and China Scholarship Coucil (202009545007).

Data Availability Statement: The dataset presented in this study is available from the corresponding author on reasonable request.

Conflicts of Interest: The authors declare no conflict of interest.

\section{References}

1. Wang,L., Yang,J., Yin, S. Electronic commerce international logistics performance influence factor analysis.International journal of mobile communications:IJMC; 2015 ,13, 498-509. doi: 10.1504/IJMC.2015.070965

2. Tseng, T.S. The Study on Cross Border E-Commerce Startup. . International Conference on Electronic Business. Proceedings; 2017,46 ,

3. Gomez-Herrera, E., Martens,B., Turlea, G. The drivers and impediments for cross-border ecommerce in the EU. Information Economics and Policy; 2014 ,28, 83-96. doi: 10.1016/j.infoecopol.2014.05.

4. Xiao,L., Yu, F. M., Yang, L.X. Target country network embedding, localized service capabilities and cross-border B2C export company performance: a theoretical explanation of overseas warehouse strategy.Business Economics and Management; 2019 ,1, 5-15. doi:10.14134/j.cnki.cn33-1336/f.2018-147975

5. Quan, Y. The necessity and practical approach of cross-border e-commerce overseas shared warehouse application. Foreign Economic Relations and Trade Practice; 2020 ,5, 32-35.doi:CNKI:SUN:DWJW.0.2020-05-010

6. $\mathrm{Xu}, \mathrm{X} . \mathrm{N}$. Research on the development status and strategy of China's cross-border logistics overseas warehouse construction in the new era. oreign Economic Relations and Trade Practice; 2019 ,9, 89-92. doi:CNKI:SUN:DWJW.0.2019-09-024

7. Saxena R. International warehousing. Industrial Engineer Ie; 2009 ,41, 22-22. doi:10.1080/0740817090280

8. Li, X.G., Wang, Q.F. The cross-border e-commerce logistics industry chain symbiosis coupling model and mechanism based on public overseas warehouses. hina Circulation Economy; 2018 ,32, 41-48. doi:CNKI:SUN:ZGLT.0.2018-09-006 
9. Liao, R.D. Difficulties and countermeasures in the use of overseas warehouses for small and medium-sized cross-border e-commerce companies' retail export (B2C). hina Circulation Economy; 2019 ,6,76-80. doi:10.13529/j.cnki.enterprise.economy.2019.06.010

10. Mo, J. Analysis and Research on the Overseas Warehouse Model of Cross-border Ecommerce.China Business Journal; 2019 ,18, 83-84.doi:10.19699/j.cnki.issn2096-0298.2019.18.083

11. Su,W.H., Wang,Y.Y. A statistical measurement of the development level of my country's cross-border e-commerce comprehensive test zone. Business Economics and Management; 2017 ,6, 13-22. doi:10.14134/j.cnki.cn33-1336/f.2017.06.002

12. Zhou, G.L., Wang, J., Su,W.H. Research on the Reform of Cross-border E-commerce Statistics Method. International Trade,; 2020 ,2, 40-47,71. doi: CNKI:SUN:GJMY.0.2020-02-007

13. Ndekwa, A.G. Drivers of Electronic Commerce (e-commerce) among Small and Medium Tourist Enterprises (SMTEs) in Tanzania.International Journal of Science and Research (IJSR); $2015,4,2512-2517$

14. Perreault, W.D., Russ, F.A. Physical Distribution Service in Industrial Purchase Decisions, Journal of Marketing Channels,; 1976 ,40, 3-10.doi: 10.1177/002224297604000203.

15. Giuffrida, M., Manglaracina, R., Perego, A., Tumino, A. Cross-border B2C e-commerce to Greater China and the role of logistics: a literature review, International. Journal of Physical Distribution Logistics Management 2017, 47, 772-795.

16. Mentzer, J.T., Williams, L.R. The Role of Logistics Leverage in Marketing Strategy, Journal of Marketing Channels; 2001 ,8, 29-47. doi: 10.1300/J049v08n03-03

17. Sun, K. Analysis of the pros and cons of overseas warehouses and the study of future development countermeasures, Foreign Economic and Trade; 2016 ,6, 29-31. doi:10.3969/j.issn.20953283.2016.06.010

18. Heller, R., Hindle, T.Essential Manager's Manual Dorling Kindersley; 2008 ,83-96.doi:9781405328388 
